Abstracta Iranica

Revue bibliographique pour le domaine irano-aryen

Volume 40-41 | 2019

Comptes rendus des publications de 2017-2018

\title{
Caroline Arnould-Behar. « Le décor des autels à encens de la Palestine perse »
}

\section{Astrid Nunn}

\section{(2) OpenEdition}

1 Journals

\section{Édition électronique}

URL : http://journals.openedition.org/abstractairanica/48386

DOI : 10.4000/abstractairanica.48386

ISBN : 1961-960X

ISSN : 1961-960X

Éditeur :

CNRS (UMR 7528 Mondes iraniens et indiens), Éditions de l'IFRI

Référence électronique

Astrid Nunn, «Caroline Arnould-Behar. « Le décor des autels à encens de la Palestine perse » »,

Abstracta Iranica [En ligne], Volume 40-41 | 2019, document 34, mis en ligne le 15 juillet 2019, consulté le 24 avril 2021. URL : http://journals.openedition.org/abstractairanica/48386 ; DOI : https://doi.org/ 10.4000/abstractairanica.48386

Ce document a été généré automatiquement le 24 avril 2021

Tous droits réservés 


\title{
Caroline Arnould-Behar. « Le décor des autels à encens de la Palestine perse »
}

\author{
Astrid Nunn
}

\section{RÉFÉRENCE}

Caroline Arnould-Behar. « Le décor des autels à encens de la Palestine perse »,

Transeuphratène 49, 2017, p. 57-66

1 Cet article est en quelque sorte un complément à Christian Frevel - Katharina Pyschny, „Perserzeitliche Räucherkästchen: Zu einer wenig beachteten Fundgattung im Kontext der These E. Sterns" in Frevel, C., Pyschny, K., Cornelius I. (éds), A "Religious Revolution in Yehûd"? The material Culture of the Persian Period as a Test Case, (OBO 267), 2014, p. 111-220. En effet l'A. traite du même matériel, mais limite son étude à trois types de motifs: Les motifs architecturaux, le palmier et les symboles astraux (étoile, disque et cercles concentriques). Ces décors non figuratifs possèdent néanmoins une valeur symbolique et ont occupé une place importante dans le répertoire décoratif de la Palestine. Parmi eux le chapiteau proto-éolien et le palmier sont particulièrement courants. La symbolique est solaire et astrale mais pas lunaire. Le répertoire est "conservateur" pour le fond, ce qui n'empêche pas une liberté de traitement. Il est très peu touché par l'iconographie ni achéménide ni égyptienne. 


\section{AUTEURS}

\section{ASTRID NUNN}

Université de Munich 